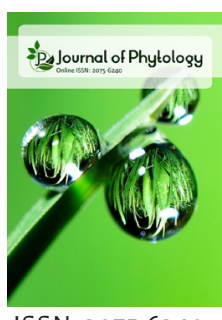

ISSN: $2075-6240$

\title{
Effects of glycine betaine on plant growth and performance of Medicago sativa and Vigna unguiculata under water deficit conditions
}

\author{
Hanan Kamal Khadouri, Karthishwaran Kandhan, Mohammed Abdul Salem* \\ Department of Aridland Agriculture, College of Food and Agriculture, PO Box No. 15551, United Arab Emirates \\ University, Al Ain, UAE
}

\begin{abstract}
Managing water consumption of the crops is one of the strategies which have been adopted locally and worldwide in current trends of sustainable agriculture. In addition to the low level of water resources in UAE because of the rare precipitation, no fresh, free-flowing water, rivers, lakes or streams. The present study was aimed to evaluate the effects of exogenous Glycine Betaine (GB) on Alfalfa (Medicago sativa) and Cowpea (Vigna unguiculata) within different levels of drought stress. A pot experiment was designed on a completely randomized block design (CRBD) with three replicates. Exogenous GB was applied as a foliar spray in three levels $(0,100$ and $200 \mathrm{ppm})$ five times with five days intervals. Drought stress starts within the second GB treatment in three levels (24h: 100\% well-watered), (48h: 60\% water deficit) and (72h: 40\% water deficit) depending on the required quantity. Growth characteristics, pigment concentrations, biochemical content and Mineral nutrients levels were measured in response to the treatment variables. Results showed that the GB has a significant increment in Growth parameters, biochemical contents, and Mineral nutrients concentrations. The results of the present investigation suggested that the exogenous application of GB was improved the drought tolerance in Cowpea and has enhanced the Alfalfa performance under drought stress in both concentrations 100 and 200 ppm under drought stress of $60 \%$ of irrigations water. In due of comparison of Cowpea and Alfalfa, it's found from this study that GB has a better effect on the Cowpea under drought stress than Alfalfa.
\end{abstract}

*Corresponding Author: Dr. Mohammed Abdul Salem Email: mohammed.s@uaeu. ac.ae

KEYWORDS: Drought stress, glycine betaine, compatible solutes, alfalfa, cowpea

\section{INTRODUCTION}

More than any other environmental factor, permanent or temporary water deficit stress limits the growth and distribution of natural and artificial vegetation and the performance of cultivated plants. Among the environmental stresses, the abiotic stresses, drought has been identified as one of the major global problems in the future and will face a major challenge for crop production in the arid and semi-arid regions in particular [1]. Water shortages are one of the major environmental stresses that restrict crop growth and productivity around the world, while global warming and climate change are making the situation more urgent, posing a major threat to global food security [2].

Productive and sustainable agriculture in arid and semi-arid regions requires growing plants with less input of valuable resources such as fresh water. Although basic studies and practices have been carried out for many years to improve resistance to soil water stress and efficiency of plant water use, the mechanisms involved at various scales are still not clear. Plants have evolved numerous defensive mechanisms to acclimatize to adverse conditions for continued growth and surviva [3]. Osmotic adjustment is an adaptive mechanism involving drought or salinity tolerance that allows turgor to be maintained under conditions of water deficit [3].

Further understanding and manipulating soil-plant-water relationships and soil-water stress tolerance at the scales of ecology, physiology and molecular biology can significantly improve plant productivity and environmental quality [4]. Feed grass such as Alfalfa and cowpea is required in the area for important suggestions such as grazing and soil conservation, but their growth is highly dependent on soil moisture and therefore needs to adopt alternative ways to maintain plant water consumption under low precipitation conditions in the country.

Copyright: $\odot$ The authors. This article is open access and licensed under the terms of the Creative Commons Attribution License (http://creativecommons.org/licenses/by/4.0/) which permits unrestricted, use, distribution and reproduction in any medium, or format for any purpose, even commercially provided the work is properly cited. Attribution - You must give appropriate credit, provide a link to the license, and indicate if changes were made. 
Cowpea (Vigna unguiculata (L.) Walp.) is an important food legume and a valuable component of the traditional cropping systems in semi-arid tropics. The young leaves, green pods and green seeds of cowpea are used as vegetables and dry seeds are used in various food preparations [5]. Cowpea is also equally important as nutritious fodder for livestock. Alfalfa (Medicago sativa L.) is one of the main fodder crops grown in the UAE. This species requires large quantities of water, often drawn from nonrenewable groundwater sources. In order to meet the increased demand for forage, large - scale cultivation of Alfalfa has resulted in a drastic reduction in groundwater levels and an increase in salinity due to seawater intrusion, particularly in coastal areas.

Glycine betaine (GB) is an organic compound that occurs in plants; it is an amphoteric quaternary amine that plays an important role as a compatible solution in plants under different types of environmental stress, such as high salt levels and high or low temperatures [6]. Generally, GB protects the plants from stress through different courses, including contribution to cellular osmotic adjustment, detoxification of reactive oxygen species, protection of membrane integrity, and stabilization of enzymes/proteins [7]. So the present study was designed to examine (i) the effect of applying the exogenous organic osmolet GB on the growth and performance of alfalfa and cowpea which have been exposure on irrigation regimes within the stress conditions of drought and high temperature in UAE environment (ii) to determine the minimum level of irrigation can the plants adopted with support of GB and compared with the controls for each of alfalfa and cowpea that have not applied with GB (iii) to comparison between these two forage plants in their responses to GB within irrigation regimes exposure.

\section{MATERIALS AND METHODS}

\section{Experimental Site and Design}

The research was conducted during rising period beneath natural conditions at Al-Foah Experimental farm, College of Food and Agriculture, UAEU, Al Ain, in the sheltered greenhouse. Alfalfa and Cowpea seeds were kindly provided by agricultural inputs marketable provider "SHAT AL ARAB". Seed sowing was carried out manually with 6 seeds/pot, in PVC cylinder pots. Germination was on the third day in Alfalfa and on the fourth day of sowing in Cowpea, after appearance 11 DAS (Days after Sowing), the seedlings were thinned to retain three seedlings in each pot.

\section{Application of Glycine Betaine Treatments and Irrigation}

Alfalfa and Cowpea were subjected to different concentrations of Glycine Betaine (GB). GB was applied in three different concentrations, 0 ppm (control), $100 \mathrm{ppm}$ and $200 \mathrm{ppm}$. Manually over the top of the plant covering all over the plants leaves, by using Pressurized Spray Bottle with $0.1 \%$ as surface spreader and applied for five times on the plants at 25, 30, 35, 40 and 45 DAS.

The water deficits factors were expressed at different irrigation intervals and fixed water quantity $(400 \mathrm{ml})$. The irrigation intervals were every 24 hours (WW -100\% - control), each 48 hours (WD - 60\%) and every 72 hours (WD - 40\%). Water was applied by controlled dripper irrigation system (Surface drip (DI) and subsurface drip irrigation (SDI) is the most effective way to convey directly water and nutrients to plants and not only, does it save water but it also increases yields of vegetable crops [8].

For each treatment early morning, the plants were subjected for water deficit regimes 31 DAS or exactly after the second application of GB. The experiment had three levels for both variables. Consequently, the research covered 9 treatments including the control units, in three replicates for each treatment in total 27 units in three sets arranged for the research in Alfa alfa and the same arrangement for the Cowpea (Chart 1).

On the 159 DAS (days after sowing) or 68 DAT (days after treatments) in Alfalfa, and on the 114 DAS 68 DAT for Cowpea, plants were harvested for analysis.

\section{Morphological Parameters}

Shoot height was measured from the soil level to the tip of the shoot and expressed in $\mathrm{cm}$. The plant root length was measured from the point of the first cotyledonary node to the tip of the longest root and expressed in $\mathrm{cm}$. Fresh weight for Shoot and Root was determined by using an electronic balance (Model XK3190-A7M) and the values were expressed in grams. Stem diameter $(\mathrm{cm})$ was measured for each plant by Vernier caliper and the values were expressed in $\mathrm{mm}$. The total number of pods, which were fully developed, were counted and expressed as number of pods per plant. Fresh weights of values were expressed in grams.

\section{Physiological Parameters}

Chlorophyll and carotenoid were extracted from the leaves and estimated by the method of Arnon (1949) [9]. Carotenoid content was estimated using the formula of Kirk and Allen (1965) [10] and expressed in milligrams per gram fresh weight. Total phenol was estimated by the method of Malick and Singh (1980) [11]. The total phenol was determined using a standard curve prepared with different concentrations of gallic acid. Proline content was estimated following the method of Bates et al. (1973) [12]. The proline content was determined from a standard curve prepared with proline and the results were expressed in milligram per gram dry weight.

\section{Estimation of Glycine Betaine}

The samples were extracted and estimated following the method of Grieve and Grattan (1983) [13]. The acid potassium triiodide solution for total QACs was prepared by dissolving $7.5 \mathrm{~g}$ resublimed iodine and $10 \mathrm{~g}$ potassium iodide in $1 \mathrm{M} \mathrm{HCI}$ and filtered (Speed and Richardson, 1968) [14]. Two ml of ice-cold water was added rapidly to the mixture to reduce the absorbance of blank and to improve replication. This was quickly followed by $10 \mathrm{ml}$ of 1, 2-dichloroethene in ice, and the 2 layers mixed well and kept at $4^{\circ} \mathrm{C}$ (Storey and Wyn Jones 1977) [15]. The 
Khadouri, et al.

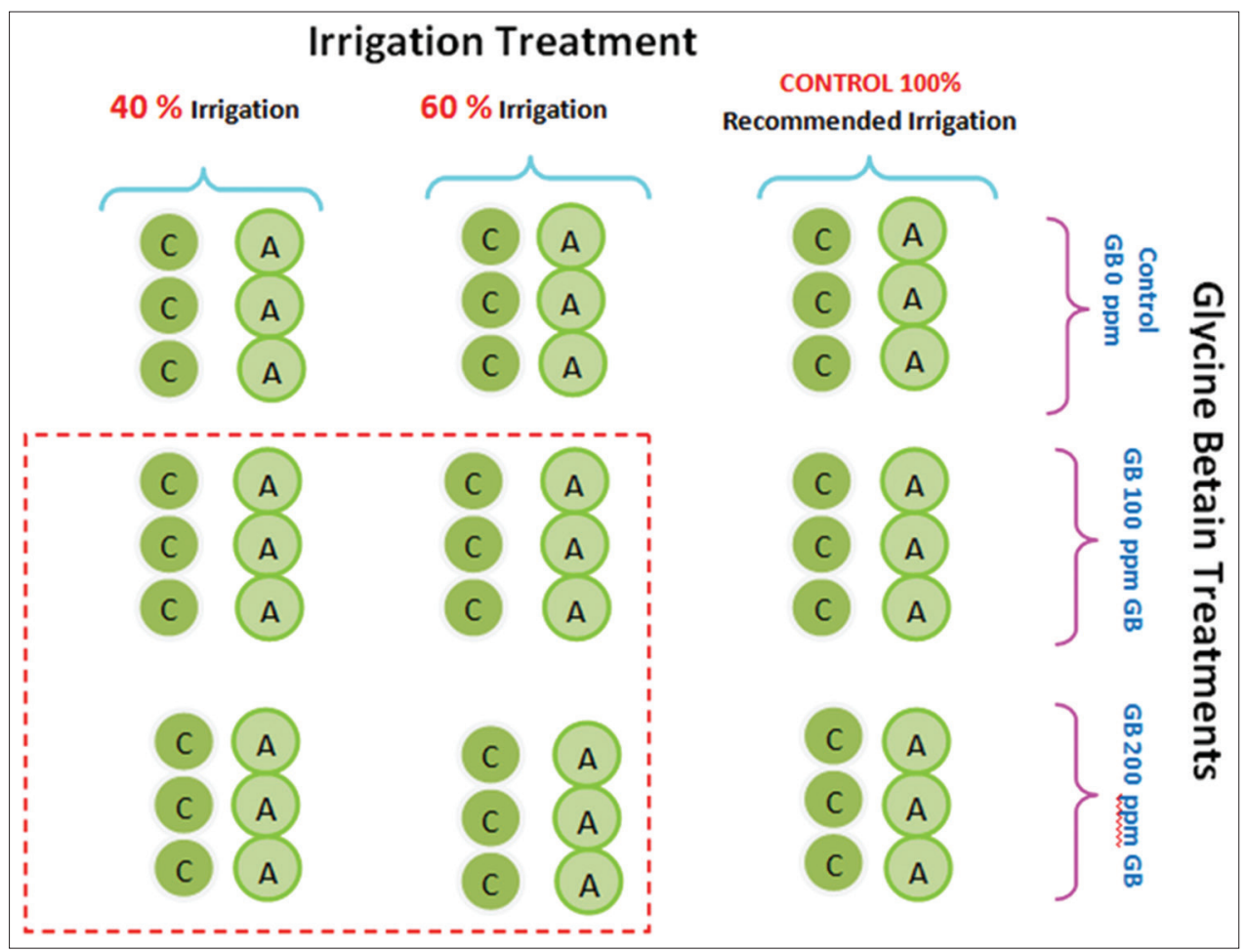

Chart 1: Treatments and Irrigation design

absorbance of the lower organic layer was measured at $365 \mathrm{~nm}$ in a Spectrophotometer. The results were expressed as glycine betaine equivalent by using glycine betaine for standard value.

\section{Elemental Analysis}

The samples were air dried then oven dry at $105^{\circ} \mathrm{C}$ for 3 hrs and the samples were ground and stored in a desiccator for further analysis. The digestion procedure was based upon the recommendation in the USEPA method 3015A guidelines. The plant samples were prepared accurately by weighing 0.5 grams of sample into the microwave digestion vessels and adding $10 \mathrm{ml}$ of concentrated nitric acid (HNO3) and $2 \mathrm{ml}$ hydrochloric acid (HCL) (Method 3015A, US Environmental Protection Agency, 2008) [16]. The vessels were capped and placed in the microwave digestion system. The reagent blank contains the same volumes of all reagents used in the processing of the samples.

\section{Statistical Analysis}

The data pertained to all the characters studied were subjected to statistical analysis using SPSS-21.0 Version. The values were meant for three replicates of all the treatments and control. The calculated data expressed in Mean $\pm \mathrm{SE}$.

\section{RESULTS}

\section{Shoot Height and Root Length}

The effect of GB, drought stress and their combination induced changes on morphology and physiological changes of Cowpea and alfalfa are presented in Tables 1 and 2. Shoot length in Cowpea was decreased under drought stress conditions treatments when compared with the control. While with the application of exogenous GB individually and with drought stress, it's induced to increase the shoot height in treatment $100 \mathrm{ppm}$ application of GB and in treatments of both 100 and $200 \mathrm{ppm}$ under drought stress of $60 \%$ of water irrigation. In alfalfa, the shoot height of drought-stressed plants was declined. With the application of GB, the shoot height was increased significantly, in drought stress treatments with applying GB the shoot height was decreased except the treatment of $60 \%$ of water with 100 ppm of GB which was increased the shoot height.

\section{Shoot Fresh and Dry Weight}

In cowpea, the shoot fresh and dry weight was significantly decreased within water stress treatments and within the application of GB. Shoot biomass in beans decreased by $32 \%$ in response to water stress compared to untreated control plants. In alfalfa, the shoot fresh weight was decreased under drought stress with or without exists of GB except with treatment of individually applying GB 100 ppm it increased the fresh weight of the plant significantly. But the shoot dry weight was increased highly in conditions of drought stress with and without GB application.

\section{Estimation of Chlorophyll and Carotenoid Content}

Chlorophyll 'A' and 'B' and total chlorophyll content were decreased in Cowpea and alfalfa under drought stress treatments with or without application of GB, but in applications of GB individually, Chlorophyll 'A', 'B' and total Chlorophyll were increased significantly in both 100 and 200 ppm of GB treatments in both the plants. The Carotenoid content in 


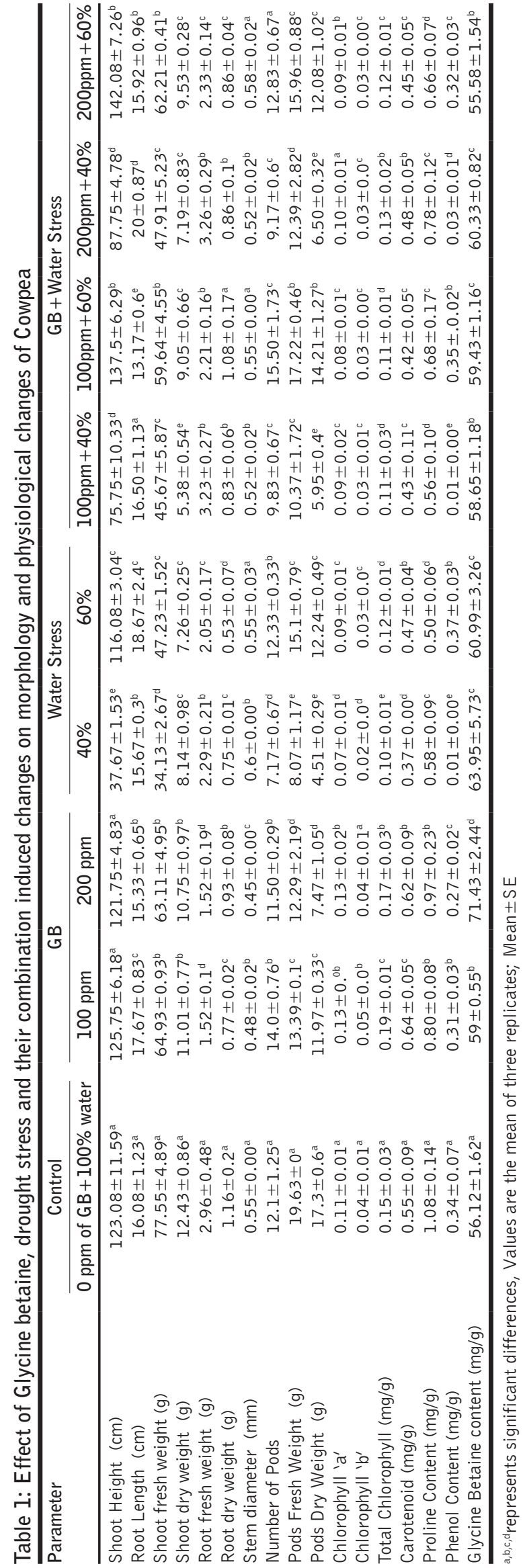

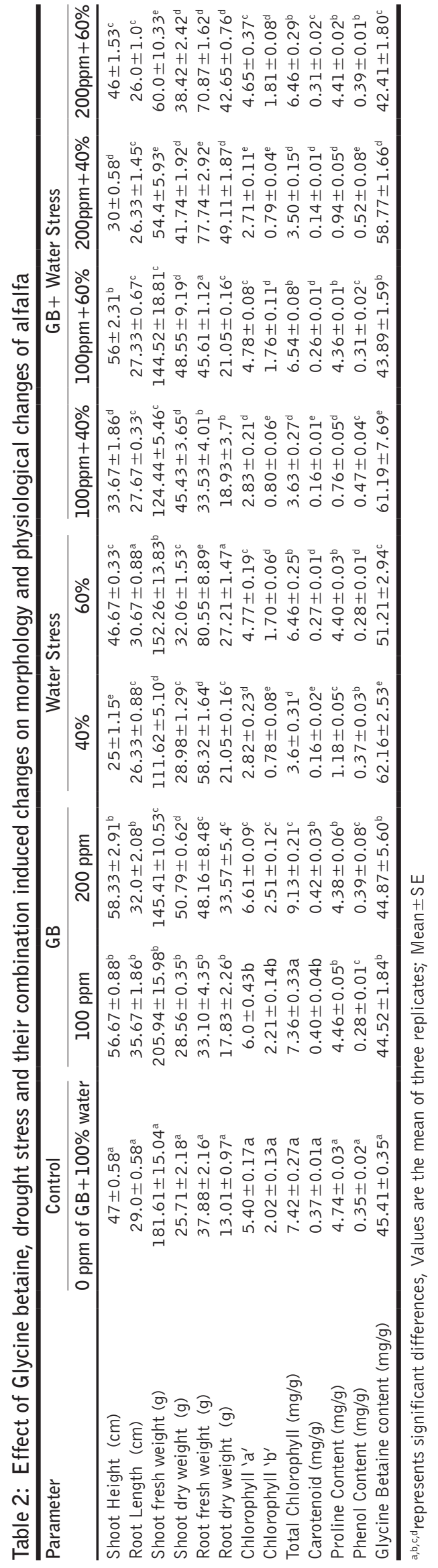

Journal of Phytology 
Cowpea and alfalfa was increased with GB treatments both 100 and $200 \mathrm{ppm}$. Drought stress decreased the carotenoid content in all treatments $40 \%$ and $60 \%$ of irrigation water and it was high decreased in alfalfa and also in the treatments of combining the applying of GB with the drought stress.

\section{Estimation of Total Phenols and Proline Content}

The phenols content of the leaves in Cowpea was reduced in the treatments of GB application, but it was increased in drought stress treatments of $60 \%$ of water without and with 100 ppm GB. In Alfalfa the application of $200 \mathrm{ppm}$ GB has induced the phenol content in the plants even when it combines the application of GB 100 and 200 ppm with the drought stress treatments of $40 \%$ and $60 \%$. It was increased the phenol levels in the leaves except for the treatment of $100 \mathrm{ppm}$ with $60 \%$ of the irrigation water the phenols level was decreased. GB content in cowpea was increased significantly in all the treatments of applications of GB and in treatments of water stress and in the combination of GB applications within the waters stress treatments. Proline content was decreased in the treatments of GB application and in the water regimes treatments and in their combination, in both plants Cowpea and Alfalfa.

\section{Estimation of Glycine Betaine}

In Alfalfa the GB content was reduced when it was applied exogenously as a foliar spray to the leaves. In the treatments of drought stress, the GB levels were rise up in both 40 and $60 \%$ of irrigation water. The combination of exogenous GB application with the drought stress conditions, the levels of GB were increased in all treatments of 100 and $200 \mathrm{ppm}$ within 40 and $60 \%$ of irrigation water, except the treatments of $60 \%$ irrigation with $200 \mathrm{ppm}$ the GB content was slightly reduced.

\section{Elemental Analysis}

The effect of GB application under drought stress conditions on the mineral nutrients contents in the Cowpea and Alfalfa are presented in Tables 3 and 4 respectively. Calcium, Potassium, Magnesium, Manganese, sodium and Zinc content showed high increased under the water stress treatments and in treatments of applying exogenously Glycine Betaine and also in treatments of combining both effects of drought stress $60 \%$ and $40 \%$ of irrigation water within application of the foliar spray Glycine Betaine and the higher increased were in treatments $200 \mathrm{ppm}$ within $60 \%$ of the irrigation water.

Calcium copper, Magnesium, Manganese, and Zinc levels were decreased within the drought treatments in Alfa alfa and also reduced with the treatments of applying Glycine Betaine. In the treatments of combining the drought stress and the applying for Glycine Betaine the Calcium level was reduced but it reduced slightly in the treatment of $100 \mathrm{ppm}$ within $60 \%$ of irrigation water.

Table 3: Effect of Glycine betaine, drought stress and their combination induced changes on mineral nutrients $\mathrm{mg} / \mathrm{Kg}$ (ppm) content of cowpea

\begin{tabular}{|c|c|c|c|c|c|c|c|c|c|}
\hline \multirow[t]{2}{*}{ Elem. } & \multirow{2}{*}{$\begin{array}{c}\text { Control } \\
0 \text { ppm of } \\
G+100 \% \text { water }\end{array}$} & \multicolumn{2}{|c|}{ GB } & \multicolumn{2}{|c|}{ Water stress } & \multicolumn{4}{|c|}{ GB+ Water stress } \\
\hline & & 100 ppm & 200 ppm & $40 \%$ & $60 \%$ & $100 p p m+40 \%$ & $100 p p m+60 \%$ & $200 p p m+40 \%$ & $200 p p m+60 \%$ \\
\hline $\mathrm{Ca}$ & $2.9 \pm 0.06^{a}$ & $3.47 \pm 0.18^{b}$ & $4 \pm 0.11^{c}$ & $3.73 \pm 0.26^{c}$ & $3.03 \pm 0.27^{b}$ & $3.07 \pm 0.12^{b}$ & $3.17 \pm 0.19^{b}$ & $2.43 \pm 0.12^{c}$ & $3.77 \pm 0.25^{c}$ \\
\hline $\mathrm{Cu}$ & $5.45 \pm 0.52^{\mathrm{a}}$ & $4.61 \pm 0.31^{b}$ & $4.34 \pm 0.17^{b}$ & $4.81 \pm 0.04^{b}$ & $3.65 \pm 0.02^{c}$ & $6.19 \pm 1.06^{b}$ & $4.17 \pm 0.18^{b}$ & $3.58 \pm 0.18^{c}$ & $3.87 \pm 0.07^{c}$ \\
\hline $\mathrm{Fe}$ & $0.02 \pm 0.00^{\mathrm{a}}$ & $0.02 \pm 0.00^{\mathrm{a}}$ & $0.01 \pm 0.00^{\mathrm{b}}$ & $0.04 \pm 0.02^{\mathrm{d}}$ & $0.04 \pm 0.00^{d}$ & $0.03 \pm 0.01^{c}$ & $0.03 \pm 0.00^{c}$ & $0.03 \pm 0.00^{c}$ & $0.04 \pm 0.01^{\mathrm{d}}$ \\
\hline $\mathrm{K}$ & $0.84 \pm 0.08^{\mathrm{a}}$ & $1.09 \pm 0.05^{c}$ & $1.08 \pm 0.09^{c}$ & $0.77 \pm 0.02^{b}$ & $0.95 \pm 0.1^{b}$ & $1.37 \pm 0.03^{e}$ & $1.04 \pm 0.11^{\mathrm{d}}$ & $1.1 \pm 0.06^{\mathrm{d}}$ & $1.2 \pm 0.12^{\mathrm{e}}$ \\
\hline $\mathrm{Mg}$ & $0.66 \pm 0.02^{\mathrm{a}}$ & $0.85 \pm 0.01^{c}$ & $0.84 \pm 0.02^{c}$ & $0.12 \pm 0.01^{d}$ & $0.84 \pm 0.05^{c}$ & $0.9 \pm 0.03^{d}$ & $0.77 \pm 0.01^{b}$ & $0.85 \pm 0.08^{c}$ & $0.84 \pm 0.05^{c}$ \\
\hline $\mathrm{Mn}$ & $46.65 \pm 5.23^{a}$ & $41.69 \pm 5.06^{c}$ & $64.66 \pm 2.41^{c}$ & $90.19 \pm 11.21^{\mathrm{a}}$ & $35.25 \pm 2.15^{\mathrm{e}}$ & $55.84 \pm 4.72^{c}$ & $51.50 \pm 1.38^{c}$ & $38.40 \pm 1.85^{\mathrm{e}}$ & $60.13 \pm 4.86^{d}$ \\
\hline$P$ & $0.34 \pm 0.04^{\mathrm{a}}$ & $0.32 \pm 0.02^{\mathrm{b}}$ & $0.3 \pm 0.02^{c}$ & $0.25 \pm 0.01^{d}$ & $0.18 \pm 0.01^{\mathrm{e}}$ & $0.24 \pm 0.03^{d}$ & $0.31 \pm 0.02^{b}$ & $0.14 \pm 0.01^{\mathrm{e}}$ & $0.26 \pm 0.01^{d}$ \\
\hline S & $0.33 \pm 0.03^{a}$ & $0.50 \pm 0.05^{d}$ & $0.31 \pm 0.00^{b}$ & $0.43 \pm 0.03^{c}$ & $0.37 \pm 0.02^{c}$ & $0.47 \pm 0.03^{d}$ & $0.31 \pm 0.02^{b}$ & $0.51 \pm 0.05^{e}$ & $0.36 \pm 0.01^{b}$ \\
\hline $\mathrm{Zn}$ & $92.44 \pm 8.76^{a}$ & $105.49 \pm 14.89^{c}$ & $65.54 \pm 2.60^{c}$ & $93.61 \pm 3.68^{b}$ & $62.22 \pm 2.42^{c}$ & $88.71 \pm 8.27^{b}$ & $43.32 \pm 2.77^{\mathrm{e}}$ & $65.63 \pm 2.97^{d}$ & $53.93 \pm 7.12^{c}$ \\
\hline
\end{tabular}

$a, b, c, d$ represents significant differences, (Values are the mean of three replicates)

Table 4: Effect of glycine betaine, drought stress and their combination induced changes on mineral nutrients content mg/Kg (ppm) of alfalfa

\begin{tabular}{|c|c|c|c|c|c|c|c|c|c|}
\hline \multirow[t]{2}{*}{ Elem. } & \multirow{2}{*}{$\begin{array}{c}\text { Control } \\
0 \text { ppm of } \\
\mathrm{GB}+100 \% \text { water }\end{array}$} & \multicolumn{2}{|c|}{ GB } & \multicolumn{2}{|c|}{ Water stress } & \multicolumn{4}{|c|}{$\mathrm{GB}+$ Water stress } \\
\hline & & 100 ppm & 200 ppm & $40 \%$ & $60 \%$ & 100ppm+40\% & $100 p p m+60 \%$ & $200 p p m+40 \%$ & $200 p p m+60 \%$ \\
\hline $\mathrm{Ca}$ & $4.10 \pm 0.46^{a}$ & $3.77 \pm 0.12^{b}$ & $3.20 \pm 0.06^{c}$ & $2.37 \pm 0.09^{d}$ & $3.77 \pm 0.09^{b}$ & $3.07 \pm 0.09^{c}$ & $3.53 \pm 0.12^{b}$ & $3.0 \pm 0.00^{c}$ & $2.83 \pm 0.15^{c}$ \\
\hline $\mathrm{Cu}$ & $15.70 \pm 0.94^{a}$ & $15.39 \pm 0.69^{b}$ & $15.52 \pm 1.13^{b}$ & $12.77 \pm 0.85^{c}$ & $15.10 \pm 0.81^{b}$ & $13.73 \pm 0.29^{c}$ & $17.83 \pm 0.20^{c}$ & $11.63 \pm 0.74^{d}$ & $12.68 \pm 0.39^{c}$ \\
\hline $\mathrm{Fe}$ & $0.30 \pm 0.03^{a}$ & $0.25 \pm 0.01^{b}$ & $0.26 \pm 0.03^{b}$ & $0.17 \pm 0.00^{c}$ & $0.25 \pm 0.23^{b}$ & $0.16 \pm 0.02^{d}$ & $0.29 \pm 0.01^{d}$ & $0.18 \pm 0.01^{c}$ & $0.16 \pm 0.02^{c}$ \\
\hline K & $0.90 \pm 0.03^{a}$ & $0.89 \pm 0.03^{b}$ & $0.74 \pm 0.03^{d}$ & $0.78 \pm 0.04^{c}$ & $0.79 \pm 0.05^{c}$ & $0.750 .05^{d}$ & $0.68 \pm 0.01^{d}$ & $0.60 \pm 0.00^{\mathrm{e}}$ & $0.62 \pm 0.02^{e}$ \\
\hline $\mathrm{Mg}$ & $1.36 \pm 0.22^{\mathrm{a}}$ & $0.95 \pm 0.03^{c}$ & $0.01 \pm 0.06^{\mathrm{e}}$ & $0.74 \pm 0.02^{d}$ & $0.89 \pm 0.45^{c}$ & $0.83 \pm 0.07^{d}$ & $1.21 \pm 0.07^{b}$ & $0.78 \pm 0.00^{c}$ & $0.74 \pm 0.04^{d}$ \\
\hline $\mathrm{Mn}$ & $106.61 \pm 7.61^{a}$ & $71.86 \pm 2.12^{b}$ & $74.00 \pm 3.62^{b}$ & $52.64 \pm 0.73^{c}$ & $88.65 \pm 6.41^{d}$ & $71.87 \pm 5.51^{d}$ & $88.86 \pm 5.15^{d}$ & $59.33 \pm 2.22^{c}$ & $57.06 \pm 1.94^{c}$ \\
\hline $\mathrm{Na}$ & $0.32 \pm 0.02^{\mathrm{a}}$ & $0.37 \pm 0.03^{b}$ & $0.44 \pm 0.01^{c}$ & $0.39 \pm 0.04^{b}$ & $0.29 \pm 0.03^{c}$ & $0.35 \pm 0.03^{b}$ & $0.38 \pm 0.01^{b}$ & $0.48 \pm 0.01^{d}$ & $0.48 \pm 0.03^{d}$ \\
\hline S & $0.19 \pm 0.00^{\mathrm{a}}$ & $0.23 \pm 0.01^{b}$ & $0.21 \pm 0.01^{b}$ & $0.19 \pm 0.1^{\mathrm{b}}$ & $0.16 \pm 0.1^{c}$ & $0.21 \pm 0.00^{\mathrm{b}}$ & $0.22 \pm 0.0^{b}$ & $0.17 \pm 0.00^{c}$ & $0.19 \pm 0.01^{b}$ \\
\hline $\mathrm{Zn}$ & $125.36 \pm 11.36^{a}$ & $115.98 \pm 8.18^{b}$ & $107.67 \pm 8.93^{c}$ & $121.23 \pm 6.90^{b}$ & $166.66 \pm 7.24^{d}$ & $126.67 \pm 4.78^{b}$ & $183.41 \pm 7.10^{\mathrm{e}}$ & $88.15 \pm 3.57^{d}$ & $111.45 \pm 3.45^{\circ}$ \\
\hline
\end{tabular}

$a, b, c, d$ represents significant differences, (Values are the mean of three replicates) 
In Cowpea the GB application induced was increased in Potassium, Magnesium, sulfur and Manganese content and decreased in phosphorus in both 100 ppm and 200 ppm. In treatments of water stress, the Potassium content increased in $60 \%$ of irrigation water. In treatments of combining the drought stress and application of GB, it increased the Potassium content in all treatments and it was the higher content of Potassium in treatment $100 \mathrm{ppm}$ of GB with $40 \%$ of water compared with the control.

\section{DISCUSSION}

The present study was aimed at determining the effect of Glycine Betaine exogenous application of two inverse factors and drought stress, affecting the growth and performance of Cowpea and Alfalfa forage crops. Hereby the discussion of the results is obtained from the morphology growth experiment, pigment levels, content of biochemical and mineral constituents. When applying GB 100 ppm and 200 ppm with drought stress, the root length was increased by 40 percent of irrigation water compared to the control. Shoot height and root length values increased significantly by exogenous application of GB (p<0.05) in tomato reported by (Khan et al. 2015) [17].

Reddy et al. (2013) [18] were reported that the plant height declined with water deficit and was affected by GB application only under WD60 conditions, exhibiting a 14\% increase in height with GB application. Root length in alfalfa was increased in treatments of applying GB as reported by Khan et al. (2015) [17]. While the root length in combination behaviors of drought stress and GB applications were significantly reduced. Measured growth characteristics declined linearly with increased water deficit intensity, both with and without GB application in maize [18].

Drought stress inhibited the shoot growth significantly in Cowpea and Alfalfa studied. Similar results were observed in avocado [19], Pearl millet [20], Populus species [21] and Petroselinum crispum [22]. A decrease in shoot length can prevent excess water loss by reducing a number of active stomata and the rate of transpiration. Drought stress increased the root length in Eucalyptus microtheca seedlings [23], Populus species, [21] Cannabis sativa [24], Parsley [22] and Triticum aestivum [25]. The development of the root system may increase the water uptake under drought stress.

GB treatments in plants subjected to long term water stress showed little or no effect in shoot biomass, as reported by Xing and Rajashkar (1999) [26]. Water deficit reduced the growth criteria (shoot fresh weight, shoot dry weight, leaf area) significantly. Total fresh weight of leaves was decreased under drought stress and total dry weight of leaves was increased significantly in drought conditions and by exogenous application of GB [17]. Changing resource pools (e.g., water or nutrient availability) may also affect the distribution of biomass in rice seedlings and sunflower [27]. Drought stress decreases both the relative variation in plant biomass and the concentration of mass within a small fraction of the population as confirmed in the earlier studies on Quercus rubra [28].
In cowpea, the root fresh weight was increased within the higher water stress $40 \%$ of irrigation water compared with control. Increased root growth was reported by Tahir et al. [29] in mango tree under water stress. But, the root dry weight was decreased within the drought stress and in applications of GB Decreased total dry weight may be due to the considerable decrease in plant growth, photosynthesis and canopy structure as indicated by leaf senescence during drought stress in Poplar species [30], Vicia faba [31]

The Chlorophyll content of the mature leaves of tomato, which were unfolded at a high temperature, was significantly high in the Crud Extract CE-applied plants compared to the Pure Extract PE-applied and control plants, reported by Kanechi et al. [32] A reduction in chlorophyll content was reported in drought-stressed soybean plants [33]. The chlorophyll content in the wheat leaf decreased due to chemical desiccation treatments (Shao et al. [34] The chlorophyll content decreased to a significant level at higher water deficits in maize and wheat plants [35] and in Lysimachia minoricensis. [36] A reduction in chlorophyll content was also reported in drought-stressed Pinus halepensis [37] and cotton [38]. GB did not improve Chl. 'b' and carotenoids of Sorghum plants grown under the stress conditions. Reduced carotenoid content under drought was reported in sunflower, [39] Prairie grasses, [40] Wheat, [41] and Litchi chinensis (Damour et al. 2008) [42].

Proline content was decreased in the treatments of GB application and in the water regimes treatments and in their combination, in both plants Cowpea and Alfalfa. Increased proline accumulation was reported in water-stressed wheat [43] and Bell pepper. Increased proline in the stressed plants may be an adaptation to overcome the stress conditions. The similar results were observed in wheat [44] and sorghum [45]. Proline accumulation in plants might be a scavenger and acting as an osmolyte. The reduced proline oxidase may be the reason for increasing proline accumulation. Proline accumulated under stressed conditions supplies energy for growth and survival and thereby helps the plant to tolerate stress [46] and bell pepper [47]. Proline may act as a non-toxic osmotic solute preferentially located in the cytoplasm or as an enzyme protectant, stabilizing the structure of macromolecules and organelles. Accumulated proline may supply energy to increase salinity tolerance [48]. Proline as an osmoprotectant compound plays a major role in osmoregulation and osmotolerance [49]. However, its definite role in exerting stress resistance continues to be a debate [50]. The development of root system increases the water uptake and maintains requisite osmotic pressure through higher proline levels in Phoenix dactylifera (Alonso et al. 2001) [37]. A rapid decrease in proline levels after stress release may be one factor in the resumption of growth after stress which is also an important determinant of overall stress tolerance [51].

The increased amount of GB content was observed under drought stress in barley [52], and in higher plants [53]. Aliphatic quaternary ammonium compounds (QAS) such as GB, stachydrine, homostachydrine, trigonelline have been found to accumulate in a large number of plants exposed to 
salt and water stress. The accumulation of GB might serve as an intercellular osmoticum and it can be closely correlated with the elevation of osmotic pressure [48]. The glycine betaine content increased under drought stress in Radix astragali [54]. GB is an important quaternary ammonium compound, is considered to be one of the most predominant and effective osmoprotectants. It is well established that its exogenous application might have some advantages as it improves drought tolerance in plants. It has been also reported earlier that the rate and timing of GB application significantly affect drought tolerance ability of sunflower (Iqbal et al. 2008) [55].

\section{CONCLUSION}

Application of GB it enhances the GB accumulation level in the plant and increased it under drought stress. There was no effect of GB on the Pigments Chlorophyll 'A', 'B', total Chlorophyll and Carotenoid within the drought stress on the plants. GB has a significant effect on raising up the phenols levels in Alfalfa within the drought stress. Exogenous applications of GB were enhanced the GB accumulation level in the plants within the drought stress of $40 \%$ of irrigation water. GB applications increased the Heavy metals levels in plants like $\mathrm{Ca}, \mathrm{Cu}, \mathrm{Fe}, \mathrm{K}$, $\mathrm{Mg}$ and $\mathrm{Mn}$. From the results obtained from the experiments, it can conclude that the GB has significant effects to ameliorate the drought stress on the Cowpea. As a conclusion of the effect of GB on the Alfalfa growth and production under the drought stress, GB it's enhanced the plants performance under the drought 56 stress in both concentrations 100 and 200 ppm. In due of comparison of Cowpea and Alfalfa it's found from this study that the GB has a better effect on the Cowpea under drought stress than Alfalfa. GB can have dual benefits: improving the yield of the product under drought and supply of micronutrient to plants.

\section{AUTHOR'S CONTRIBUTIONS}

All the authors are contributed equally in the experiment. In which, first author HKK has carried out the experiment and interpreted the data. MAS has designed the experiment, guided and validated the manuscript. Similarly, KK participated in the review of the manuscript.

\section{REFERENCES}

1. Barutçular C, El Sabagh A, Koç M, Ratnasekera D. Relationships between Grain Yield and Physiological Traits of Durum Wheat Varieties under Drought and High Temperature Stress in Mediterranean Conditions. Fresenius Environmental Bulletin. 2017;26: 4282-4291.

2. Campbell BM, Vermeulen SJ, Aggarwal PK., Corner-Dolloff C, Girvetz E, Loboguerrero AM, Ramirez-Villegas J, Rosenstock T, Sebastian L, Thornton PK, Wollenberg E. Reducing risks to food security from climate change Global Food Security. 2016;34-43.

3. Wani SH, Singh NB, Haribhushan A, Mir JI. Compatible Solute Engineering in Plants for Abiotic Stress Tolerance - Role of Glycine Betaine. Current Genomics. 2013;14: 157-165.

4. Shao HB, Chu LY, Jaleel CA, Manivannan P, Panneerselvam R, Shao, MA. Understanding water deficit stress-induced changes in the basic metabolism of higher plants-biotechnologically and sustainably improving agriculture and the eco-environment in arid regions of the globe. Critical Reviews in Biotechnology. 2009;29:131-51.

5. Singh BB, Ajeigbe HA, Tarawali SA, Fernandez-Rivera S, Abubakar M.
Improving the production and utilization of cowpea as food and fodder. Field crops Research. 2003;84: 169-177.

6. Sakamoto A, Murata N. The role of glycine betaine in the protection of plants from stress: clues from transgenic plants. Plant Cell and Environment. 2002; 25:163-171.

7. Giri J. Glycine betaine and abiotic stress tolerance in plants. Plant Signal and Behavior. 2011;1746-1751.

8. Selim T, Berndtsson R, Persson M. Simulation of soil water and salinity distribution under surface drip irrigation. Irrigation and Drain. 2013; 62:352-362.

9. Arnon DI. Copper enzymes in isolated chloroplasts. Polyphenoloxidase in Beta vulgaris. Plant physiology. 1949; 24: p.1.

10. Kirk JTO, Allen RL. Dependence of chloroplast pigment synthesis on protein synthesis: effect of actidione. Biochemical and Biophysical Research Communications 1965; 21:523-530.

11. Malick CP, Singh MB. Plant Enzymology and Histoenzymology. Kalyani Publishers, New Delhi. 1980.

12. Bates LS, Waldren RP, Teare ID. Rapid determination of free proline for water-stress studies. Plant and soil. 1973;39:205-207.

13. Grieve CM, Grattan SR. Rapid assay for determination of water soluble quaternary ammonium compounds. Plant Soil. 1983;70:303-307.

14. Speed D, Richardson M. Chromatographic methods for the isolation and identification of the products of choline oxidation. Journal of Chromatography. 1968;35:497-505.

15. Storey R, Jones RW. Quaternary ammonium compounds in plants in relation to salt resistance. Phytochemistry. 1977; 16:447-453.

16. Sample digestion methods. Sample digestion methods: Microwave assisted digestion of aqueous samples and extracts (Method 3015A), 2008. EPA Test Methods Online (SW-846). www.epa.gov/epawaste/ hazard/testmethods/sw846/pdfs/3015a.pdf

17. Khan SU, Khan, A, Naveed S. Effect of exogenously applied kinetin and glycinebetaine on metabolic and yield attributes of rice (Oryza sativa L.) under drought stress. Emirates Journal of Food Agriculture. 2015; 27:75-81.

18. Reddy KR, Henry WB, Seepaul R, Lokhande S, Gajanayake B, Brand D. Exogenous Application of Glycine betaine Facilitates Maize (Zea mays L.) Growth under Water Deficit Conditions. American Journal of Experimental Agriculture. 2013:3:1-13.

19. Chartzoulakis K., Patakas A., Kofidis G, Bosabalidis A, Nastou A. Water stress affects leaf anatomy, gas exchange, water relations and growth of two avocado cultivars. Scientia horticulturae. 2002;95:39-50.

20. Kusaka M, Ohta M, Fujimura T. Contribution of inorganic components to osmotic adjustment and leaf folding for drought tolerance in pearl millet. Physiologia Plantarum. 2005;125:474-489.

21. Yin C, Wang, X, Duan B, Luo J, Li C. Early growth, dry matter allocation and water use efficiency of two Sympatric populus species as affected by water stress. Environmental and Experimental Botany. 2005;53:315-322.

22. Petropoulos SA, Daferera D, Polissiou MG, Passam HC. The effect of water deficit stress on the growth, yield and composition of essential oils of parsley. Scientia Horticulturae 2008;115:393-397.

23. Li C, Berninger F, Koskela J, Sonninen E. Drought responses of Eucalyptus microtheca provenances depend on seasonality of rainfall in their place of origin. Functional Plant Biology. 2000;27:231-238.

24. Amaducci S, Zatta A, Pelatti F, Venturi G. "Influence of agronomic factors on yield and quality of hemp (Cannabis sativa L.) fibre and implication for an innovative production system." Field Crops Research. 2008; 107:161-169.

25. Dickin E, Wright D. The effects of winter waterlogging and summer drought on the growth and yield of winter wheat (Triticum aestivum L.). European Journal of Agronomy. 2009;28:234-244.

26. Xing $W$, Rajashekar CB. Alleviation of water stress in beans by exogenous glycine betaine. Plant Science. 1999;148:185-195.

27. Soriano MA, Orgaz F, Villalobos FJ, Fereres E. Efficiency of water use of early plantings of sunflower. European Journal of Agronomy. 2004;21:465-476.

28. Weber JA, Gates DM. Gas exchange in Quercus rubra during a drought: Analysis of relation among photosynthesis, transpiration and conductance. Tree Physiology. 1990;7:215-225.

29. Tahir FM, Ibrahim M, Hamid K. Effect of drought stress on vegetative and reproductive growth behaviour of mango (Mangifera indica L.). Asian Journal of Plant Sciences. 2003;2:116-118.

30. Ren J, Dai W, Xuan Z, Yao Y, Korpelainen H, Li C. The effect of drought and enhanced UV-B radiation on the growth and physiological traits 
of two contrasting poplar species. Forest Ecology and Management. 2007;239:112-119.

31. Wu DX, Wang GX. Interaction of $\mathrm{CO}_{2}$ enrichment and drought on growth, water use, and yield of broad bean (Vicia faba). Environmental and Experimental Botany. 2000;43:131-139.

32. Kanechi M, Hikosaka Y, Uno Y. Application of sugar beet pure and crude extracts containing glycine betaine affects root growth, yield, and photosynthesis of tomato grown during summer. Scientia Horticulturae. 2013;152: 9-15.

33. Zhang M, Duan, L, Tian X, He Z, Li J, Wang B, Li Z. Uniconazoleinduced tolerance of soybean to water deficit stress in relation to changes in photosynthesis, hormones and antioxidant system. Journal of Plant Physiology. 2006;164:709-717.

34. Shao HB, Chen XY, Chu LY, Zhao XN, Wu G, Yuan YB, Zhao CX, Hu ZM. Investigation on the relationship of proline with wheat anti-drought under soil water deficits. Colloids and Surfaces B: Biointerfaces. 2006;53:113-119.

35. Nayyar H, Gupta D. Differential sensitivity of $\mathrm{C}_{3}$ and $\mathrm{C}_{4}$ plants to water deficit stress: association with oxidative stress and antioxidants. Environmental and Experimental Botany. 2006;58:106-113.

36. Galmes J, Abadia A, Medrano H, Flexas J. Photosynthesis and photoprotection responses to water stress in the wild-extinct plant Lysimachia minoricensis. Environmental and Experimental Botany. 2007;60:308-317

37. Alonso R, Elvira S, Castillo FJ, Gimeno BS. Interactive effects of ozone and drought stress on pigments and activities of antioxidative enzymes in Pinus halepensis. Plant, cell and environment. 2001;9:905-916.

38. Massacci A, Nabiev SM, Pietrosanti L, Nematov SK, Chernikova TN, Thor K, Leipner J. Response of the photosynthetic apparatus of cotton (Gossypium hirsutum) to the onset of drought stress under field conditions studied by gas-exchange analysis and chlorophyll fluorescence imaging. Plant Physiology Biochemistry. 2008;46:189-195.

39. Gimenez K, Mitchell V, Lawlor D. Regulation of photosynthetic rate of two sunflower hybrids under water stress. Plant Physiology. 1992;9 8:516-524.

40. Heckathorn SA, DeLucia EH, Zielinski RE. The contribution of droughtrelated decreases in foliar nitrogen concentration to decreases in photosynthetic capacity during and after drought in prairie grasses. Physiologia Plantarum. 1997;101:173-182.

41. Sawhney $V$, Singh DP. Effect of chemical desiccation at the postanthesis stage on some physiological and biochemical changes in the flag leaf of contrasting wheat genotypes. Field Crop Research. 2002;77:1-6.

42. Damour G, Vandame M, Urban L. Long-term drought modifies the fundamental relationships between light exposure, leaf nitrogen content and photosynthetic capacity in leaves of the lychee tree (Litchi chinensis). Journal of plant physiology. 2008;165:1370-1378.

43. Hamada AM. Amelioration of drought stress by ascorbic acid, thiamine or aspirin in wheat plants. Indian Journal of Plant Physiology. 2000;5: 358-364.

44. Vendruscolo ACG, Schuster I, Pileggi M, Scapim A, Molinari HBC Marur CJ, Vieira LG. Stress-induced synthesis of proline confers tolerance to water deficit in transgenic wheat. Journal of Plant Physiology. 2007;164:1367-1376.

45. Yadav SK, Lakshmi NJ, Maheswari M, Vanaja M, Venkateswarlu B. Influence of water deficit at vegetative, anthesis and grain filling stages on water relation and grain yield in sorghum. Indian Journal Plant Physiology. 2005;10: 20-24.

46. Jaleel CA, Gopi R, Sankar B, Manivannan P, Kishorekumar A, Sridharan R, Panneerselvam R. Studies on germination, seedling vigour, lipid peroxidation and proline metabolism in Catharanthus roseus seedlings under salt stress. South African Journal of Botany. 2005;73:190-195.

47. Nath AK, Kumari S, Sharma DR. In vitro selection and characterization of water stress tolerant cultures of bell pepper. Indian Journal of Plant Physiology. 2005; 10:1419.

48. Jaleel CA, Manivannan P, Kishorekumar A, Sankar B, Gopi R, Somasundaram R, Panneerselvam R. Alterations in osmoregulation, antioxidant enzymes and indole alkaloid levels in Catharanthus roseus exposed to water deficit. Colloids and Surfaces B: Biointerfaces. 2007;59:150-157.

49. Salama HM, Al Watban AA, Al-Fughom AT. Effect of ultraviolet radiation on chlorophyll, carotenoid, protein and proline contents of some annual desert plants. Saudi Journal of Biological Sciences. 2011;18:pp.79-86

50. Demiral T, Turkan I. Exogenous glycinebetaine affects growth and proline accumulation and retards senescence in two rice cultivars under $\mathrm{NaCl}$ stress. Environ Environmental and Experimental Botany. 2006;56:72-79.

51. Hayano-Kanashiro C, Calderon-Vazquez C, Ibarra-Laclette E, HerreraEstrella L, Simpson J. Analysis of gene expression and physiological responses in three Mexican maize landraces under drought stress and recovery irrigation. PLoS ONE 2009;4:e7531.

52. Nakamura T, Nomura M, Mori H, Jagendorf AT, Ueda A, Takabe T. An isozyme of betaine aldehyde dehydrogenase in barley. Plant and Cell Physiology. 2001;42:1088-1092.

53. Jun HR, Adam LH, Rozwadowski KL, Hammerlineli JL, Keller WA, Selvaraj G. Genetic engineering of glycinebetaine production towards enhancing stress tolerance in plants. Plant Physiology. 2000;122:747-56.

54. Tan Y, Zongsuo L, Hongbo S, Feng D. Effect of water deficits on the activity of anti-oxidative enzymes and osmoregulation among three different genotypes of Radixastragali at seedling stage. Colloids Surfaces B: Biointerfaces. 2006;49:60-65.

55. Iqbal N, Ashraf M, Ashraf MY. Glycinebetaine, an osmolyte of interest to improve water stress tolerance in sunflower (Helianthus annuus L.): water relations and yield." South African Journal of Botany. 2008;74:274-281. 